\title{
CIRUGÍA PLÁSTICA IBERO-LATINOAMERICANA ON-LINE
}

¡Enhorabunena!. Cirugía Plástica Iberolatinoamericana ha superado todos los requisitos necesarios para ser admitida en la Plataforma SciELO (Scientific Electronic Library Online), y a partir de este Númerolde 2006 estará disponible para su consulta en Internet en la página web http://www.scielo.org

La plataforma SciELO forma parte de la red de información Biblioteca Virtual en Salud. En la actualidad permite el acceso a artículos a texto completo de 250 revistas científicas pertenecientes a 20 materias, de modo totalmente gratuito y desde cualquier ordenador conectado a Internet.

Esto supone un gran paso adelante para nuestra publicación que de esta manera, y tras 32 años de edición, entra en una nueva era de rápida difusión a todos los países miembros de la FILACP, de acceso inmediato a todos nuestros lectores de España, Portugal e Iberoamérica, y que nos permite llegar también a otros colegas del resto del mundo que comparten con nosotros un idioma común cada vez más difundido.

Nuestra Revista podrá por fin estar presente en las bases de datos bibliográficas e índices de impacto internacionales.

Queremos desde estas páginas hacer partícipes a todos los miembros de la FILACP de esta importante noticia y dar también las gracias a todos cuantos han participado en su consecución: a la Secretaria General de la FILACP, Dra.Manuela Berrocal, al Director de la Fundación Docente de la FILACP, Dr. Wilfredo Calderón, a nuestra Editorial en España, Gabinete de Divulgación Científica, S.L., y al personal de SciELO España por su amabilidad y entusiasmo en el proyecto, especialmente a Elena Primo y Cristina Bojo.

Finalmente agradecer el patrocinio de MENTOR IBERICA que ha permitido la materialización de este proyecto.

Dra. Mạ del Mar Vaquero Pérez

Directora de Cirugía Plástica IberoLatinoamericana

\section{Patrocinado por :}




\section{INFORMACIÓN GENERAL SOBRE SCIELO}

\section{El modelo de publicación electrónica SciELO}

\section{El proyecto}

SciELO - Scientific Electronic Library Online forma parte de la red de información Biblioteca Virtual en Salud, proyecto resultante de la cooperación entre la Fundação de Amparo à Pesquisa do Estado do São Paulo (Fapesp) y el Centro Latinoamericano y del Caribe de información en Ciencias de la Salud (B ireme) de la Organización Panamericana de la Salud-Organización Mundial de la Salud (OPS/OMS).

El proyecto surge inicialmente 1997 en Brasil y se desarrolla para dar solución al problema de la escasa representación de la literatura científica de América Latina y El Caribe, en las bases de datos bibliográficas e índices de impacto internacionales.

Actualmente están plenamente desarrollados 6 sitios SciELO, 5 geográficos (SciELO Brasil, SciELO Chile, SciELO Cuba, SciELO España y SciELO Venezuela) y uno temático (SciELO Salud Pública). En proceso de desarrollo encontramos sitios como: Argentina, Colombia, Brasil Proceedings o Brasil Tesses. Todos estos sitios se reúnen en una red conformada por las diferentes colecciones nacionales y temáticas. Desde esta red (http://www.scielo.org) se puede acceder a todas las colecciones y hacer búsquedas simultáneas en todas ellas.

\section{Modelo ScIELO}

SciELO se puede definir como un modelo de publicación electrónica cooperativa de revistas científicas en Internet que proporciona una solución eficiente para asegurar la visibilidad y el acceso universal a la literatura científica.

Su principal objetivo es contribuir al desarrollo de la investigación, mejorando y ampliando los medios de difusión, publicación y evaluación de sus resultados, creando para ello una red de bibliotecas, con colecciones nacionales de publicaciones científicas en formato electrónico. Sus objetivos más específicos son:

- Facilitar el control bibliográfico de la literatura científica.

- Aumentar la difusión de las publicaciones.

- Posibilitar la evaluación de su uso e impacto.

- Mejora la calidad de las mismas, tanto en su aspecto formal como en su contenido.

\section{El modelo de SciELO España}

(Plataforma de Cirugía Plástica IberoLatinoamericana)

El proyecto en España nace del convenio de colaboración entre la Organización Panamericana de la Salud y el Instituto de Salud Carlos III, que administran el proyecto a través de los centros BIREME, por parte de la OPS y la Biblioteca Nacional de Ciencias de la Salud (BNCS) por parte del Instituto.

SciELO España es un modelo de publicación electrónica que proporciona el acceso al texto completo a revistas editadas en España sobre Ciencias de la Salud y que han sido seleccionadas de acuerdo a unos criterios de calidad preestablecidos.

El proyecto en España comenzó a desarrollar entre 1999 y 2000 cuando se formo el equipo de trabajo y se implanto la infraestructura técnica. La colección comenzó con cuatro revista y en la actualidad cuenta con 26. SciELO España es una herramienta dinámica en continuo desarrollo, prueba de ello está en el constante crecimiento de su colección desde que comenzó:

FASE PILOTO (1999-2001)

- $\quad$ Anales de Medicina Interna

- Medifam

- Revista de Diagnóstico Biológico

- Revista Española de Salud Pública 
- Gaceta Sanitaria

- The European J ournal of Psychiatry (edición española)

- RCOE

- Archivos de la Sociedad Española de Oftalmología

8 revistas 1301 artículos

\section{PRESENTACIÓN OFICIAL (2003)}

- Educación Médica

- Anales del Sistema Sanitario de Navarra

- Cuadernos de Medicina Forense

- Actas Urológicas Españolas

- Nutrición Hopitalaria

\section{3 revistas 2191 artículos}

\section{FASE DE DESARROLLO (I) (2004)}

- Revista Española de Cirugía Oral y Maxilofacial

- Medicina Oral, Patología Oral y Cirugía Bucal

- Revista de la Sociedad Española del Dolor

- Oncología (Barcelona)

- Index de Enfermería

- Revista Española de Enfermedades Digestivas

- Revista de la Sociedad Española de Enfermería Nefrológica

\section{1 revistas 3193 artículos}

\section{FASE DE DESARROLLO (II) (2005)}

- Neurocirugía

- Archivos Españoles de Urología

- The European J ournal of Psychiatry

- Avances en Odontoestomatología

- Avances en Periodoncia e Implantología Oral

\section{6 revistas 5297 artículos}

\section{FASE DE DESARROLLO (III) 2006. NUEVAS INCOR PORACIONES}

\section{- Cirugía Plástica Ibero-Latinoamericana}

- Gerokomos

- Pharmacy Practice

- Revista de psicología del trabajo y de las organizaciones

- Psicología educativa

- Intervención psicosocial

- Clínica y Salud

- Medicina Intensiva

En el futuro SciELO España pretende ser referente de calidad y una fuente de información válida y representativa de las revistas de Ciencias de la Salud Española. 